\author{
V International Forum on Teacher Education
}

\title{
The Specifics of Media Literacy Development Among Future Teachers in Studying Pedagogic Disciplines
}

\author{
Natalia V. Fedoseeva * (a), Yelena V. Levkina (b) \\ (a), (b) National Research Nizhny Novgorod State University named after N.I. Lobachevsky, Arzamas branch, \\ Arzamas city, Russia
}

\begin{abstract}
The relevance of the study is due to the need for future teachers' media literacy development and insufficient development of organizational and pedagogic conditions for the implementation of such development in studying pedagogic disciplines. The article is aimed at determining the organizational and pedagogic conditions for the media literacy development, disclosing the means of development of students' media literacy while studying pedagogic disciplines. The leading method of research is the experimental use of media literacy development' tools taking into account organizational and pedagogic conditions in teaching pedagogic disciplines, which makes it possible to consider this problem as a process of purposeful and conscious mastering future teachers' abilities to use media tools in their professional activities. The article justifies and describes the organizational and pedagogic conditions of media literacy development, defines the means of its development (QR-generator, QR-scanner, stikbot, a group in social networks called "Pedagogic education") taking content and features of pedagogic subjects teaching into account. The creation of such conditions during the organization of classes of pedagogic disciplines is aimed at forming future teachers' readiness to carry out professional and pedagogic activities in the framework of modern education.
\end{abstract}

Keywords: Media literacy, means of media literacy development, organizational and pedagogic conditions of media literacy development.

\section{(C) 2019 Natalia V. Fedoseeva, Yelena V. Levkina}

This is an open access article distributed under the terms of the Creative Commons Attribution License (CC BY 4.0), which permits unrestricted use, distribution, and reproduction in any medium, provided the original author and source are credited.

Published by Kazan Federal University and peer-reviewed under responsibility of IFTE-2019 (V International Forum on Teacher Education)

\section{Introduction}




\subsection{Relevance of the study}

The digital economy necessitates forming a number of important skills among the younger generation. The following skills are supposed to ensure successful future: navigating in various fields of knowledge, quick self-reorganizing while searching for the necessary informing, demonstrating high motivation, willingness to perform professional activities, presenting own ideas, promoting and popularizing them, attracting colleagues to cooperate for the implementation, sharing products. All these skills are related to media literacy. Students can master them only while the teacher himself or herself owns them and involves students in their implementation. On the other hand, these skills are important in most professional and pedagogic activity, for the exchange of positive experience, the platform for which are the forums, congresses, conferences, symposia, and just pedagogic and methodological advice. The implementation of the "Modern digital educational environment in the Russian Federation" priority project also implies the possession of media literacy among teachers and students. The issues of media literacy and mobile education are actively raised during UNESCO events (mobile learning Week, from 4 to 8 March 2019, UNESCO headquarters in Paris (France)).

Therefore, it is no coincidence that an indispensable requirement for professional teaching activities is media literacy of the future teacher as it indicated in Professional teacher standard (Ministry of Labor and Social Protection, 2013).

\subsection{Methodological support}

However, it is necessary to comprehend and consider in detail the problem of identifying organizational and pedagogic conditions and means of media literacy development and organizational and pedagogic conditions for the implementation of such development while studying pedagogic disciplines. In this regard, it is advisable to identify the organizational and pedagogic conditions of organizing the most effective media literacy development and to characterize the means of students' media literacy development. Future teachers' media literacy development will be more intensive with the use of QR generator, QR scanner, stikbot mobile applications and demonstrative capabilities of the social network in the course of studying pedagogic disciplines.

A number of aspects of forming media literacy and media education are considered and studied. However, the organizational and pedagogic conditions of media literacy development while studying pedagogic disciplines are not described in detail, the means of media literacy development when working in the classroom for pedagogy are not characterized. In this regard, understanding the role of mobile applications and demonstration capabilities of the group in social networks as means of media literacy development, their interpretation as a way of self-expression, drawing attention to the best teaching experience, exchanging the ideas and concepts, the definition of media literacy as a necessary quality of the teacher necessary for professional and pedagogic activities implementation and collaboration with colleagues, understanding and further improving the activities (competence-based and practice-oriented approaches to the forming of readiness for professional and pedagogic activities), reliance on an integrative approach to media literacy development implementation in the development pedagogic disciplines will make it possible to have a new view at the forming future teachers' media literacy.

The study outlines the principals (didactic and methodological) that determine the specifics of organizational and pedagogic conditions of media literacy.

Organizational and pedagogic conditions for future teachers' media literacy development while studying pedagogic disciplines that will make the process of their development more effective, are considered, described, justified; means of media literacy development are selected and presented; their 
capabilities in conjunction with pedagogic disciplines for forming future teachers' readiness for professional and pedagogic activity.

During the work on the study, the choice and conditions of the use of media literacy development tools for teachers while working with materials on pedagogic disciplines were justified, allowing future teachers to be guided in the organization of the education process by the choice of media training tools; their opportunities for representing pedagogic materials, demonstrating their ideas, self-expressing through the work with the material of pedagogic disciplines were also shown.

\subsection{Literature analysis}

The problem of media literacy scientists studied for a long time. The following aspects were considered: media literacy as the quality of the future human (Kuzmin, Zhilavskaya, \& Ignatova, 2014), a strategic framework for the media literacy development (Fateeva, 2015), the justification of bibliographic tools in the forming of media literacy, media literacy in the context of teacher competence (Stolbnikova, 2006), understanding of the concepts and phenomena in the system of linguistic knowledge represented in Zhilavskaya (2009). In the works of Fedorov (2015) a deep theoretical analysis of the concept of media literacy in the activities of the teacher, its relationship with media competence, methodological and conceptual foundations of media literacy were analysed. In a number of publications we can find some issues of media literacy forming in the educational environment (Kuzina, 2017; Kuzina \& Mironycheva, 2014).

Suvi Tuominen (Finnish Centre for Media Education and Audiovisual Media), Sirkku Houseman (Professor of media Literacy and Education, University of Tampere, Finland) (Tuominen \& Kotilainen, 2012), Anniina Lundvall ( coordinator of Finnish Society on Media Education) (Ludwell, 2012), Marjo LAAKKONEN (Marjo Laakkonen) University of Tampere) (LAAKKONEN 2012) dismantle various aspects of problems of forming of media literacy. They give the definition of media and informing literacy from the standpoint of practice-oriented approach to the educational process, innovative approach to teaching; they show examples of the organizing work with the media in the educational space of a school and a class.

However, the issue of media literacy development concerning the development of pedagogic disciplines in working with students studying in the field of Pedagogy and Psychology and pedagogic education is considered insufficient.

\section{Methods}

Aim of the research

The solution of the identified problems is based on the implementation of the following items: 1) studying psychological and pedagogic literature and periodicals of media literacy development in the educational process of the University, 2) justifying and characterizing the organizational and pedagogic conditions for media literacy development among future teachers in studying pedagogic disciplines, 3) describing the impact of mobile applications and demonstration capabilities of social networks on the development of students' media literacy.

\section{Research methods}

For testing and confirming this hypothesis the following research methods aimed at achieving a reliable result were chosen: a comparative analysis of the works of authors who studied (SIA) the questions of media literacy among University students, generalization and systematization of the results of the study and analyzing academic and educational literature, which makes it possible to come to the theoretic and methodological justification in the consideration of this problem, the reasonable choice of means of media literacy Pedagogy. Empirical methods of research to test the hypothesis were observations of first and 
second-yesr students, surveys, analysis of the data obtained as a result of the pedagogical experiment.

The groups included students with approximately equal opportunities in the field of pedagogic disciplines.

Stages of research

The experiment was conducted in three stages. Initially, the organizational and pedagogical conditions for the use of mobile applications and the group's opportunities in social networks for the development of media literacy of students were justified. The basic principles of organising conditions were adequate visualization of the studied material, which organically intertwined the use of a mobile application, the implementation of the methodological framework, the interpretation of educational content necessary for the analysis and understanding the pedagogical reality; taking into account the characteristics of the profile and the subject under study at the presentation of applications or other means of formation of media literacy; systematic and consistent work with applications and demonstration means of the group in the social network; the continuity of stages in the development of applications and educational material at the same time.

Therefore, the organizational and pedagogic conditions of the use of mobile applications and the group's capabilities concerning future teaches' media literacy development include:

University ;

taking the outlined principles into account when organizing the educational process of the

- step-by-step organization of the system of lectures or seminars on pedagogic disciplines weaving them into the canvas of active and interactive methods and forms of training;

- a meaningful and appropriate selection of applications, that is necessary in class for achieving goals and objectives (as there may occur a QR crossword puzzle with the transition to the studied topic, a small analysis of the applications, appropriateness, video analysee, etc., while the systematic use of them still needs to happen in the course of seminars);

- taking the features of the audience (for students of "Biology and Geography" as an organizational form it is certainly more appropriate to use the proper lessons with the emphasis on the subject, while for "Psychology and social pedagogy" students combined lesson, perhaps in primary school, with emphasis on stages, methods, psychological substructure lesson, etc. is more suitable) into account;

- didactically reasonable choice of the stage of the lesson to work with the application of pedagogic disciplines;

- availability of opportunities for group and individual activities while working with pedagogically and didactically meaningful mobile applications, protecting their products;

- availability of conditions for creativity in presentating the products of students' activities.

Stage 1 of the experiment involved the diagnosis of forming media literacy among the first year students, at the end of the spring semester. The modified questionnaire of Fedorov (2004) "Knowledge of media culture terminology" was used to study media literacy. We have added questions to the questionnaire concerning mobile applications and social networking opportunities as means of media literacy development, as they are considered as such means for future teachers. Mini-tests on academic disciplines of the pedagogical cycle, expert evaluation of the teacher were also done.

The indicators developed by Fedorov (2004) are presented as the criteria of the characteristics of levels of teachers' media competence. Since in the context of our research the development of media competence takes place in the course of mastering the disciplines, we have taken only three indicators as a 
basis: informational, practice-operational and creative. By integrating them with the development of the material, it is possible to assess the degree of mastery of media literacy and the discipline itself. The high level is awareness of developments in media education, the desire to reveal new opportunities of mobile applications, social networks for self-presentation and processing the materials on pedagogical disciplines, the systematic use of mobile applications and demonstration capabilities of social networks during classes of pedagogic disciplines, creative approach in the use of media tools for the transformation, presentation and solution of pedagogical tasks, situations and coverage of materials ("History of pedagogy and education", "Theory of education and pedagogical technologies", etc.). Everything is expressed through a positive assessment of a future teacher, the performance of the final control is appropriate, the test results are not lower than $80 \%$, the sustained interest in the use of media in professional and pedagogical activities is present.

The average level is characterized by partial awareness of mobile applications and their potential as media, satisfactory knowledge in the field of organizational and pedagogical conditions of use of applications and opportunities of social networks in the educational process, the use of a limited number of applications in the simplest form for the presenting, interpreting and solving pedagogical problems and situations and the representing advanced pedagogical ideas and concepts; quantitative characteristics: good evaluation of the students' activity by the teacher, the final control indicators are positive, the results of testing in pedagogic disciplines are not lower than $70 \%$.

The low level is characterized by a very limited understanding of the use of mobile applications and social networking opportunities for media education, low awareness of modern mobile applications, media opportunities of social networks in education, the lack of skills to use them and transform the material with their help. It is expressed in a satisfactory assessment of students' activities, low indicators of final control, test results of not less than 50\%, low motivation to carry out educational activities, lack of interest in it and its organization. This phase took place in the second half of 2017 and the first half of 2018.

\section{Results}

The analysis of the results of the control and experimental group at the first stage of the study revealed that among students studying in the field of Pedagogy and Psychology is dominated by low (37\% and $38 \%$ respectively) and medium ( $45 \%$ and $45 \%$ respectively) levels of competence. The high level $-18 \%$ - was in the control group and $22 \%$-in the experimental group.

Stage 2 - experiment. For media literacy development concerning pedagogic disciplines, we used QR-generator, QR-scanner, stikbot, a group in social networks called "Pedagogic education" as well as simulation of pedagogical tasks and situations that require solutions in order to understand the conceptual apparatus of various branches of pedagogical knowledge (history of pedagogy, theory of teaching, etc.). Phasing stage was scheduled as follows. First, there was an introduction to the application, revealed by examples of opportunities for understanding the phenomena of pedagogical reality, work with educational materials. To do this, students were offered tasks performed in applications (solving crossword puzzles with QR codes, including pedagogical categories and concepts, hidden videos of pedagogical situations, etc., analysis of mini-videos made with stikbot, working with videos and other media materials in the group "Pedagogical education", etc.). Then it was offered to produce any material with the use of the applications and capabilities of the group. The final step was to perform a creative task (for example, using stikbot to create a mini-video of the pedagogical situation with the reflection of the laws of pedagogical reality for further protection or to present a group discussion and evaluation; present yourself with a QR code, etc.). It was proposed to place materials in the group teaching. 
In the control group, classes were held in the classical form of lectures and seminars without a certain emphasis on media and their capabilities, that is, they were generally certainly mentioned, but there was no purposeful work on their use as such.

In the experimental group a set of tasks (see above) which is the most, in our opinion, effectively affects the development of media literacy of future teachers was selected in the course of mastering the disciplines of the pedagogical cycle. These tools were used to identify various types of tasks that were systematically used in the classroom (QR codes in lectures and workshops, creative tasks with subsequent presentation and protection or discussion in a group on a social network).

As part of the study of "History of pedagogy and education", as part of the course "Pedagogy", used the following game tasks: solving QR crossword puzzles and code tasks on approaches to the consideration of historical and pedagogical phenomena, research methods in the history of pedagogy, the names of famous teachers, their works, crossword in school and pedagogy of Antiquity, the middle Ages, the analysis of small video sketches made in stikbot on the works of famous teachers, presentation of their findings as a result of the study of the discipline, independent creation and protection of creative works, placement of results for discussion in group.

On discipline "Theory of teaching and pedagogical technologies" was offered the same job, but on other stuff. First, students also solved QR crossword puzzles, puzzles and other game tasks on the basic concepts of the theory of learning (lesson, educational content, student, teacher, educational material, etc.), determined the laws, principles of learning, methods and techniques, structural components of the lesson, its typology in video sketches created in stikbot, defended their position, while working in the group of Pedagogical education. "Teaching methods" were held in the form of their game with QR codes, etc., "Lesson as an organizational form", "Technologies in the educational process" with the analysis of mini-video fragments of the lesson, elements of technology. Then they performed creative tasks using QR generator of crossword puzzles and other game tasks on different topics, playing in mini-scenes using stikbot application of learning technology, elements of mastering the content of education, etc.

The creative works prepared by students with the use of applications were the subject of analysis and discussion in the classroom. The opposing side asked questions, and the defenders had to justify their choice of application and interpretation of the material, present a didactic justification for its use, creatively present their work. Also, the basis for the protection of their projects were such forms of classes with students as mini-conferences and panoramas, which could cover the result of the activities of all students.

\section{The control phase of the experiment}

The control phase of the experiment was carried out during the first half of 2018. Comparison of the results of repeated diagnostics using the same questionnaires and diagnostic tasks based on the indicated indicators makes it possible to state that they were higher in the experimental group. In the control group, as well as in the experimental dynamics was observed, but it was insignificant. In the control group, the level of media literacy was: low $-30 \%$, medium $-47 \%$, high $-23 \%$. Despite the fact that number of participants in the experimental group is slightly less, there were the following percentages by levels $-25 \%, 40 \%$ and $35 \%$, respectively. This allows us to assert that under specially created organizational and pedagogical conditions of development of media literacy in the course of studying pedagogic disciplines, the level of medical literacy increases steadily.

\section{Discussion}

The study of psychological and pedagogical literature makes it possible to state the absence of special studies on the development of media literacy of future teachers in pedagogic disciplines. However, 
media literacy formation in general is presented in the works of Fedorov $(2004 ; 2015)$.

\section{Conclusion}

During the course of the experiment it was revealed that for the successful general professional competences formation concerning students studying in the in the field of Pedagogy the following aspects should be taken into account 1) "Pedagogy" discipline features, characterized by a wide range of concepts and different approaches and paradigms to the organization of the educational process, the phenomena of life, the predominance of the subject of typologies, classifications and systematization, 2) features of professional and pedagogical activities, not limited only to the framework of the educational process, and including its constant analysis, understanding, creative approach in its implementation, carried out not only personally, but also in the process of exchange with other teachers, 3) the specifics of forms, methods and techniques, as close as possible to the realities of the educational process and the conditions of pedagogical activity. Thus, we have characterized and justified the organizational and pedagogic conditions for media literacy development among students in the process of studying pedagogic disciplines, based on a number of principles and representing a system of work in the classroom, which includes step-by-step familiarization and mastering mobile applications and demonstration capabilities of the group in the social network, their creative use in performing non-traditional tasks, integration with active and interactive forms of interaction in lectures and seminars. The results of the study show the effectiveness of the proposed organizational and pedagogic conditions for media literacy development among future teachers. The presence of media literacy sets the orientation of a future teacher to an active and creative, but, at the same time, reasonable and meaningful reorganization of the educational process in order to increase its intensity and effectiveness.

\section{References}

Fateeva, I. A. (2015). New technological formats of media literacy' projects. Bulletin of Chelyabinsk State University, 5(360), 40-46.

Fedorov, A.V. (2004). Media education and media literacy. Taganrog: Kuchma publishing house.

Fedorov, A. V. (2015). Media education: history and theory. Moscow: International Social Organization "Information for everyone".

Kuzina, I. V., \& Mironycheva, F. (2014). Organization of project activities of schoolchildren on the basis of media education technologies. "Culture and education" Electronic scientific and practical journal, 11(15), 29.

Kuzina, I. V. (2017). Media education technologies in the preparing a modern Russian language and literature teacher. In T. G. Galaktionova \& E. I. Kazakova (Eds.), Preparation of a teacher of Russian language and literature in the system of higher education: problems and prospects: proceedings of the III Russian scientific and practical conference (pp. 148-151). Moscow: Centre of the Russian language and Slavic studies.

Kuzmin, Ye. I., Zhilavskaya, I. V., \& Ignatova, D. D. (2014). Media and information literacy in Russia: the road to the future. In I. V. Gilewski (Ed.), Media and information literacy in the information society: Proceedings of the Russian scientific and practical conference (p. 232). Moscow: International Center of Library Cooperation.

Ministry of Labor and Social Protection. (2013, October 18). Professional teacher standard (pedagogical activity in pre-school, primary education, basic general education, secondary general education; educator, teacher). Retrieved March 23, 2019 from http://www.consultant.ru/law/hotdocs/30085.html/ 
Stolbnikova, Ye. A. (2006). Modern teachers' media literacy as a professional competence. Media education, 2, 55-61.

Tuominen, S., \& Kotilainen, S. (2012). Pedagogical aspect of media and information literacy formation. Moscow: UNESCO.

Zhilavskaya, I. V. (2009). Media Education of youth audience. Tomsk: Tomsk Institute of Information Technology. 